\title{
Diffuse sclerosing variant of papillary thyroid carcinoma: lack of BRAF mutation but occurrence of RET/PTC rearrangements
}

\author{
Sien-Yi Sheu*, Suzan Schwertheim*, Karl Worm, Florian Grabellus and \\ Kurt Werner Schmid \\ Institute of Pathology and Neuropathology, University Hospital of Essen, Essen, Germany
}

\begin{abstract}
Diffuse sclerosing variant of papillary thyroid carcinoma (PTC) is a rare tumour with a characteristic morphology as well as a strong preponderance for younger female patients. The T1799A missense mutation in exon 15 of the BRAF gene and RET/PTC rearrangement have been identified as the dominant genetic tumour initiation events in the pathogenesis of PTC leading to a constitutive activation of the RAS-RAF-MAPK pathway. In order to elucidate the pathogenesis of diffuse sclerosing variant of PTC, the prevalence of BRAF mutation and RET/PTC were determined by RT-polymerase chain reaction and DNA-sequence analysis in tumour samples of seven patients with this variant (all female, age range 15-61 years, mean 33.3 years) without prior radiation exposure. None of these cases showed a BRAF mutation. RET/PTC1 (two out of seven) and RET/PTC3 (one out of seven), which have been shown in large PTC series to comprise together more than $90 \%$ of $R E T / P T C$ types, were found in $<50 \%$ of the cases investigated. All seven samples expressed the RET tyrosine kinase domain but lacked its extracellular domain potentially suggesting the existence of rare types of RET/PTC rearrangement in the four remained cases of diffuse sclerosing variant of PTC. Regarding this subtype, our study confirmed the paradigm of a mutual exclusivity between RET/PTC and BRAF in PTC. Additionally, this rare variant of papillary thyroid carcinoma may represent a tumour type susceptible to RET-targeted therapies. Modern Pathology (2007) 20, 779-787; doi:10.1038/modpathol.3800797; published online 27 April 2007
\end{abstract}

Keywords: BRAF; RET/PTC rearrangement; diffuse sclerosing variant of papillary thyroid carcinoma

Thyroid tumours are the most common neoplasms of the endocrine system ${ }^{1}$ with papillary thyroid carcinoma (PTC) representing the most frequent malignancy comprising approximately $80 \%$ of all thyroid cancers. ${ }^{2}$ The diffuse sclerosing variant of PTC is a rare subtype accounting for $1.8 \%$ of PTC cases in larger series. ${ }^{3}$ This subtype exhibits a higher frequency of cervical and distant metastasis ${ }^{4-6}$ affiliating with a worse prognosis, ${ }^{7,8}$ female preponderance and younger age. ${ }^{4,9}$ However, in two published series, ${ }^{10,11}$ comprising 15 and 22 patients, respectively, as well as studies with smaller numbers of cases, ${ }^{5,12}$ a prognosis similar to that of conventional PTC has been reported. First described by Vickery et $a l^{13}$ as an unusual form of PTC, this

Correspondence: Dr KW Schmid, MD, MRCPath, Institute of Pathology and Neuropathology, University Hospital of Essen, University of Duisburg-Essen, Hufelandstr. 55, D-45122 Essen, Germany.

E-mail: kw.schmid@uk-essen.de

* These authors contributed equally to this work.

Received 28 February 2007; revised 20 March 2007; accepted 27 March 2007; published online 27 April 2007 subtype is histologically characterized by dense sclerosis, extensive squamous metaplasia, patchy to dense lymphocytic infiltrates, numerous psammoma bodies, and small papillary structures within dilated lymphovascular spaces. The tumour shows involvement of one or both thyroid lobes, usually without forming a dominant mass. ${ }^{1}$

$R E T / P T C$ rearrangements represent one of the two major genetic tumour initiation events in the pathogenesis of PTC particularly in patients after radiation exposure and in children. ${ }^{14-16}$ Chromosomal rearrangements linking the promoter and $\mathrm{N}$-terminal domains of unrelated genes to the C-terminal fragment of RET result in the aberrant production of a chimeric form of the receptor in thyroid cells that is constitutively active. ${ }^{17}$ Several forms have been identified that differ according to the $5^{\prime}$ partner gene involved in the rearrangement, with $R E T /$ PTC1 and $R E T /$ PTC3 being the most common accounting for $>90 \%$ of all rearrangements. ${ }^{18}$

$B R A F$ represent one type of RAF serine/threonine kinases that play a central role in the transduction of signals along the RAS-RAF-MAPK pathway regulat- 
ing cell growth, differentiation, and apoptosis in response to cytokines, hormones, and growth factors. ${ }^{19}$ This major genetic alteration involved in the pathogenesis of PTC is an activating mutation of the $B R A F$ gene occurring in about $45 \%$ of the sporadic type (reviewed by $\mathrm{Xing}^{20}$ ) resulting in increased kinase activity of $B R A F$ with activation of ERK. $B R A F$-activating missense point mutations in the kinase domain are clustered in exons 11 and 15 of the gene. About $80 \%$ of all mutations display a thymine-to-adenine transversion at nucleotide 1799 (T1799A) leading to a substitution of valine by glutamic acid at amino-acid residue 600 (V600E) in exon $15 .^{21} B R A F$ mutation-positive tumours have been associated with various subtypes, ${ }^{20}$ older age of patients, ${ }^{22,23}$ extrathyroidal extension, ${ }^{22,24,25}$ and more advanced tumour stage at presentation. ${ }^{22,25,26}$ $B R A F$ mutations have also been linked to tumour progression from well-differentiated papillary to anaplastic carcinoma, possibly with the intermediate step of poorly differentiated carcinoma. ${ }^{24,27}$

In most series described so far, RET/PTC rearrangement and activating mutations of $B R A F$ and $R A S$ are mutually exclusive. ${ }^{28-30}$ In the light of these findings, we searched in a series of seven cases of diffuse sclerosing variant of PTC for both BRAF mutations and $R E T / P T C$ rearrangements in order to elucidate its pathogenetical background, probably providing a putative therapeutic option for this rare variant of PTC.

\section{Materials and methods}

\section{Patients and Tumour Samples}

Eight cases of the diffuse sclerosing variant of PTC diagnosed between 1999 and 2005 were retrieved from the files of the Institute of Pathology and Neuropathology, University Hospital of Essen, Germany. All samples exhibited the classical features as described by Vickery et al; ${ }^{13}$ the typical histology is depicted in Figure 1a and b. The clinical data of these eight cases are summarized in Table 1. All patients were female with an age ranging from 14 to 61 years (mean 33.3 years). To the best of our knowledge, none of the patients had a history of radiation exposure (environmental or therapeutic). All tumours showed extrathyroidal extension except one (case 2) and involved both lobes except two (cases 6 and 8). Lymph node metastases were found in six cases $(75 \%)$. One patient showed serologically Hashimoto's thyroiditis (case 3). All patients gave informed consent.

\section{Macrodissection of Tumour Tissue}

Macrodissection from paraffin-embedded specimens to obtain 'pure' tumour tissues was performed as follows: areas exhibiting exclusively tumour tissue were marked on histological slides and the
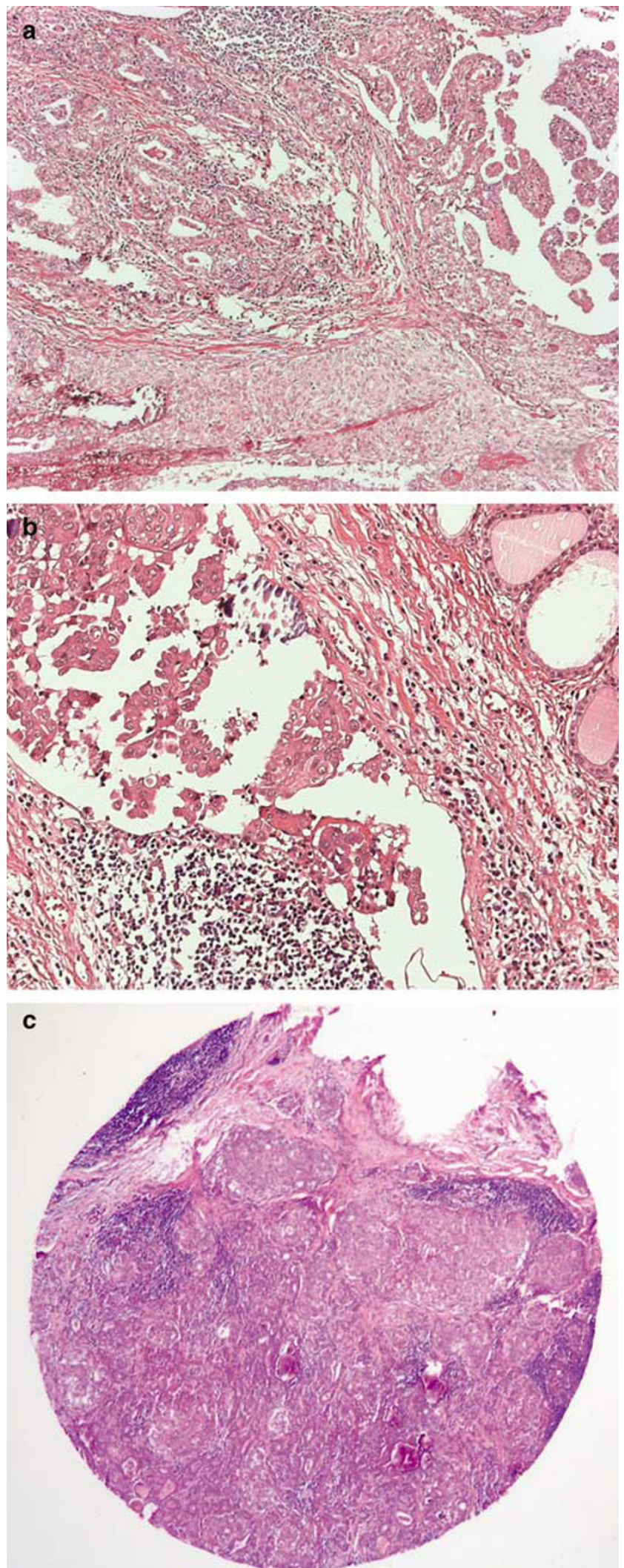

Figure 1 Diffuse sclerosing variant of PTC (hematoxylin and eosin, HE, $\times 100$ ) showing dense sclerosis, squamous metaplasia and a lymphocytic infiltrate (a). Papillary structures are located within dilated lymphovascular spaces $(\mathbf{b} ; \mathrm{HE}, \times 200)$. Representative punching cylinder of $0.2 \mathrm{~cm}$ after macrodissection for RNA extraction stained with $\mathrm{HE}(\times 80)(\mathbf{c})$. 
Table 1 Clinical characteristics and results

\begin{tabular}{lllllr}
\hline Sample & Age & Sex & TNM & Location & RET/PTC \\
\hline 1 & 61 & F & pT4N1Mx & b & 1 \\
2 & 17 & F & pT3N1Mx & b & 3 \\
3 & 14 & F & pT4N1M1 & b & b \\
4 & 15 & F & pT4N1Mx & b & TK+/EC - \\
5 & 40 & F & pT4N1Mx & b & - \\
6 & 55 & F & pT4N0Mx & r & TK+/EC - \\
7 & 40 & F & pT4NxMx & b & TK+/EC - \\
8 & 24 & F & pT4N1Mx & l & - \\
\hline
\end{tabular}

F, female; b, bilateral; r, right lobe; l,left lobe; TK+/EC -, tyrosine kinase domain positive/extracellular domain negative.

${ }^{\mathrm{a}} \mathrm{TNM}$ classification 1997 (5th edition).

${ }^{\mathrm{b}}$ Sample 3 was excluded from RET/PTC analysis due to a consistent lack of RNA integrity.

corresponding paraffin tissue blocks as previously described by Musholt et al. ${ }^{31}$ At least five tissue cylinders were obtained from the centres of tumour areas with a punching tool of $0.6 \mathrm{~mm}$ diameter and collected in a $1.5 \mathrm{ml}$ microcentrifuge tube for DNA extraction. For RNA extraction, multiple tissue cylinders of $0.2 \mathrm{~cm}$ diameter obtained as described above were re-embedded in paraffin and cut into multiple $20 \mu \mathrm{m}$ sections (Figure 1c). To avoid contamination between tumour samples, the punching tool was cleaned with $1 \%$ SDS-solution.

\section{Immunohistochemistry}

Four micrometre sections of paraffin-embedded tissues of all cases were cut and mounted onto coated slides for immunohistochemical staining. Heat-induced antigen retrieval was carried out with $0.01 \mathrm{M}$ citrate buffer at pH 6.0 for $20 \mathrm{~min}$. Specimens were stained with a polyclonal rabbit anticalcitonin antibody (dilution 1:4800; DAKO, Hamburg, Germany). Staining was detected using a biotin free enhanced polymer step staining technique (EPOS method) with a peroxidase-conjugated polymer backbone coupled with a secondary (anti-rabbit) antibody (EnVision, DAKO, Hamburg, Germany).

\section{Identification of $B R A F$ Mutation}

For analysis of $B R A F$ gene mutation, genomic DNA was isolated from the macrodissected tissues. The samples were deparaffinized by xylene/ethanol treatment. DNA was extracted using the QIAamp DNA Mini Kit (Qiagen, Hilden, Germany) according to the manufacturer's protocol.

Exon 15 of $B R A F$ was amplified by polymerase chain reaction (PCR) with the primers listed in Table 2. Briefly, $2 \mu$ l DNA was amplified with 10 pmol of each primer, $200 \mu \mathrm{M}$ deoxynucleotide triphosphates, $1 \times$ PCR Buffer (Qiagen, Hilden, Germany) and 1.25 U of Hot Star Taq DNA Polymerase (Qiagen, Hilden, Germany) in a final volume of $50 \mu \mathrm{l}$. The PCR conditions were initially denaturation at $95^{\circ} \mathrm{C}$ for $10 \mathrm{~min}$, followed by 40 cycles (denaturation at
Table 2 Primers used in this study ${ }^{16}$

\begin{tabular}{|c|c|c|}
\hline & Primer sequences $\left(5^{\prime}-3^{\prime}\right)$ & Amplicon \\
\hline c-ras & $\begin{array}{l}\text { ATG ACT GAG TAC AAA CTG GT } \\
\text { AGG AAG CCT TCG CCT GTC CT }\end{array}$ & 236 \\
\hline c-ret, TK & $\begin{array}{l}\text { GGA GCC AGG GTC GGA TTC CAG TTA } \\
\text { CCG CTC AGG AGG AAT CCC AGG ATA }\end{array}$ & 155 \\
\hline c-ret, EC & $\begin{array}{l}\text { GGC GGC CCA AGT GTG CCG AAC TT } \\
\text { CCC AGG CCG CCA CAC TCC TCA CA }\end{array}$ & 184 \\
\hline $\begin{array}{l}B R A F-\mathrm{F} \\
B R A F-\mathrm{WF}\end{array}$ & $\begin{array}{l}\text { TCA TAA TGC TTG CTC TGA TAG GA } \\
\text { CAG GGC CAA AAA TTT AAT CAG TG }\end{array}$ & 227 \\
\hline $\begin{array}{l}B R A F-\mathrm{R} \\
B R A F-\mathrm{WR}\end{array}$ & $\begin{array}{l}\text { GGC CAA AAA TTT AAT CAG TGG A } \\
\text { TGC TTG CTC TGA TAG GAA AAT GAG }\end{array}$ & 218 \\
\hline $\begin{array}{l}R E T / \mathrm{PTC} 1, \\
\text { external }\end{array}$ & , GCT GGA GAC CTA CAA ACT GA & 165 \\
\hline $\begin{array}{l}R E T / \text { PTC1, } \\
\text { internal }^{\mathrm{a}}\end{array}$ & $\begin{array}{l}\text { GTT GCC TTG ACC ACT TTT C } \\
\text { ACA AAC TGA AGT GCA AGG CA } \\
\text { GCC TTG ACC ACT ACT TTT CCA AA }\end{array}$ & 151 \\
\hline $\begin{array}{l}R E T / \mathrm{PTC} 3, \\
\text { external }\end{array}$ & $\begin{array}{l}\text { AAG CAA ACC TGC CAG TGG } \\
\text { CTT TCA GCA TCT TCA CGG }\end{array}$ & 242 \\
\hline $\begin{array}{l}\text { RET/PTC3, } \\
\text { internal }^{\mathrm{a}}\end{array}$ & $\begin{array}{l}\text {, CCT GCC AGT GGT TAT CAA GC } \\
\text { GGC CAC CGT GGT GTA CCC TG }\end{array}$ & 219 \\
\hline
\end{tabular}

${ }^{\mathrm{a}}$ Primer sequences reported by Chua et al. ${ }^{32}$

$94^{\circ} \mathrm{C}$ for $30 \mathrm{~s}$; annealing at $55^{\circ} \mathrm{C}$ for $60 \mathrm{~s}$; synthesis at $72^{\circ} \mathrm{C}$ for $60 \mathrm{~s}$ ) and a final extension at $72^{\circ} \mathrm{C}$ for $8 \mathrm{~min}$ with a Primus 25 thermocycler (MWG Biotech, Ebersberg, Germany). Amplification products were analysed on $2.3 \%$ agarose gel and purified using the Min Elute PCR Purification Kit (Qiagen, Hilden, Germany).

Nucleotide sequence analysis was performed with the BigDye Terminator v1.1 Cycle Sequencing Kit (Applied Biosystems, Foster City, CA, USA). The purified PCR products were sequenced in both directions using BRAF $\mathrm{R}$ and BRAF WR primers (Table 2), respectively. Cycle sequencing products were analysed using the ABI PRISM 310 Genetic Analyser (Applied Biosystems, Darmstadt, Germany).

Owing to an unsatisfactory product for sequence analysis in two cases (samples 5 and 7) additionally a nested PCR was performed. For the first PCR, the 
external primers BRAF $\mathrm{F}$ and BRAF WF (Table 2) were used followed by the internal and external primers BRAF R and BRAF WR for the second PCR.

A case of tall cell variant of PTC with proven T1799A mutation was processed in the same way and served as positive control.

\section{Detection of RET/PTC Rearrangements}

$R E T / P T C$ rearrangements were analysed by RT-PCR. For RNA extraction tissue cylinders of $0.2 \mathrm{~cm}$ diameter were re-embedded in paraffin and cut into multiple $20 \mu \mathrm{m}$ sections as previously described by Musholt et al. $^{31}$ One $4 \mu \mathrm{m}$ section before and one after these collected sections were stained with hematoxylin and eosin to prove tumour cells are present (Figure 1c). RNA was extracted using the RNeasy FFPE Kit (Qiagen, Hilden, Germany). Briefly, tissue sections were deparaffinized by xylene/ethanol treatment. Tissue pellets were resuspended in $150 \mu \mathrm{l}$ Buffer PKD, $20 \mu \mathrm{l}$ Proteinase $\mathrm{K}$ and incubated overnight on a shaker incubator at $56^{\circ} \mathrm{C}$. Further processing of the samples was performed according to the recommendations of the supplier. Total RNA $(1 \mu \mathrm{g})$ was reverse transcribed to complementary DNA (cDNA) with Superscript II reverse transcriptase (Invitrogen, Karlsruhe, Germany) according to the recommendations of the supplier. Amplification of c- $N$-ras with PCR was used as quality control for RNA integrity.

At first a general screening for $R E T /$ PTC rearrangements was performed by evaluation of expression of both the tyrosine kinase (TK) and extracellular (EC) domains of RET by RT-PCR as described by Nikiforov et al. ${ }^{16}$ Tumours demonstrating expression of the TK domain with lack of the EC domain were considered to be positive for RET rearrangement. A medullary (MTC) and follicular thyroid carcinoma (FTC) served as positive and negative control, respectively. The TPC 1 cell line known to harbour $R E T / \mathrm{PTC1}$ rearrangement served as positive control. All controls were embedded in paraffin and were processed in the same way as the tumour samples. The same PCR procedure was applied for the determination of RET/PTC 1 and 3 rearrangements; the primers used (Table 2) have been reported previously. ${ }^{16}$ One case of PTC that harbour RET/ PTC3 rearrangement proven by sequencing (data not shown) served as positive control. Amplification products were analysed on $2.3 \%$ agarose gel, visualized by ethidium bromide and purified using the Min Elute PCR Purification Kit (Qiagen, Hilden, Germany). The samples producing the specific TK and EC domains were sequenced for confirmation.

Subsequently, the presence of the most common types of RET rearrangement (RET/PTC1 and RET/ PTC3) were analysed in detail using the nested RTPCR assay described by Chua et al. ${ }^{32}$ For each PCR, $2 \mu \mathrm{l}$ cDNA was amplified with 10 pmol of each primer (Table 2), $200 \mu \mathrm{M}$ deoxynucleotide tripho- sphates, $1 \times$ PCR buffer (Qiagen, Hilden, Germany) and $1 \mathrm{U}$ of Hot Star Taq DNA Polymerase (Qiagen, Hilden, Germany) in a final volume of $30 \mu \mathrm{l}$. After an initial denaturation at $95^{\circ} \mathrm{C}$ for $10 \mathrm{~min}$, amplification was performed over 40 cycles consisting of $94^{\circ} \mathrm{C}$ for $30 \mathrm{~s}, 55^{\circ} \mathrm{C}$ for $45 \mathrm{~s}, 72^{\circ} \mathrm{C}$ for $45 \mathrm{~s}$, and a final extension at $72^{\circ} \mathrm{C}$ for $5 \mathrm{~min}$ in a Primus 25 Thermocycler (MWG Biotech, Ebersberg, Germany) machine. PCR products were analysed on $2.3 \%$ agarose gelatine, purified using the Min Elute PCR Purification Kit (Qiagen, Hilden, Germany) and sequenced for confirmation as described above.

\section{Results}

\section{BRAF Mutations in Tumour Samples}

All eight tumours of the present series were negative for the typical thymine $\rightarrow$ adenine missense mutation at nucleotide 1799 of the BRAF gene. Sequence analysis of a representative case (case 2) and the positive control are shown in Figure 2.

\section{RET/PTC Rearrangements Tumour Samples}

From eight cases of DSVPTC seven (all except case 3 ) had the required quality of RNA and produced the c- $N$-ras band of 236 bp (Figure 3a). Tissue samples of case 3 were analysed in triplicate without providing a satisfactory RNA extraction result; thus, we assumed that the starting material only offered poor RNA quality, omitting this case from further investigations. The examination of the remaining

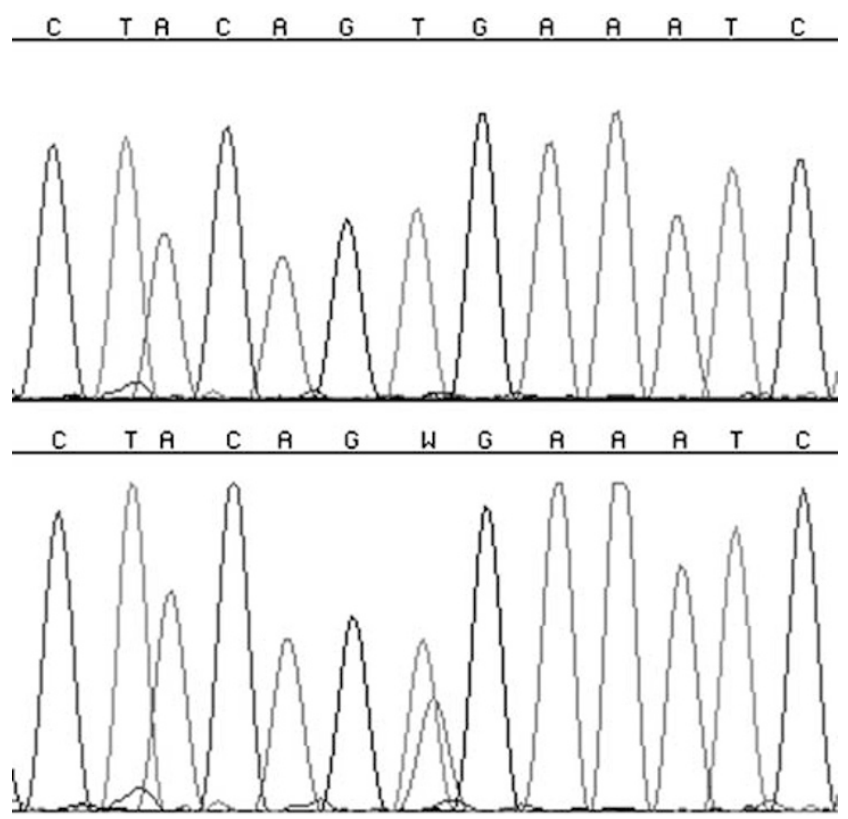

Figure 2 Sequence analysis of $B R A F$ exon 15 in one patient (case 2) showing wild-type sequence (above) and in the positive control (PTC, tall cell variant) (down) harbouring the T1799A transversion. 


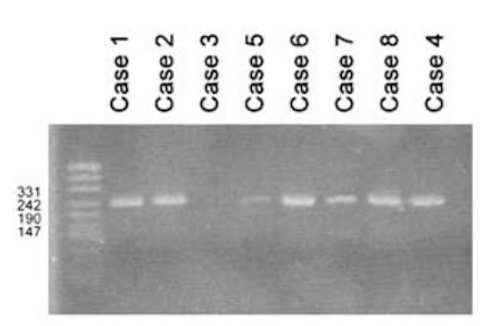

b
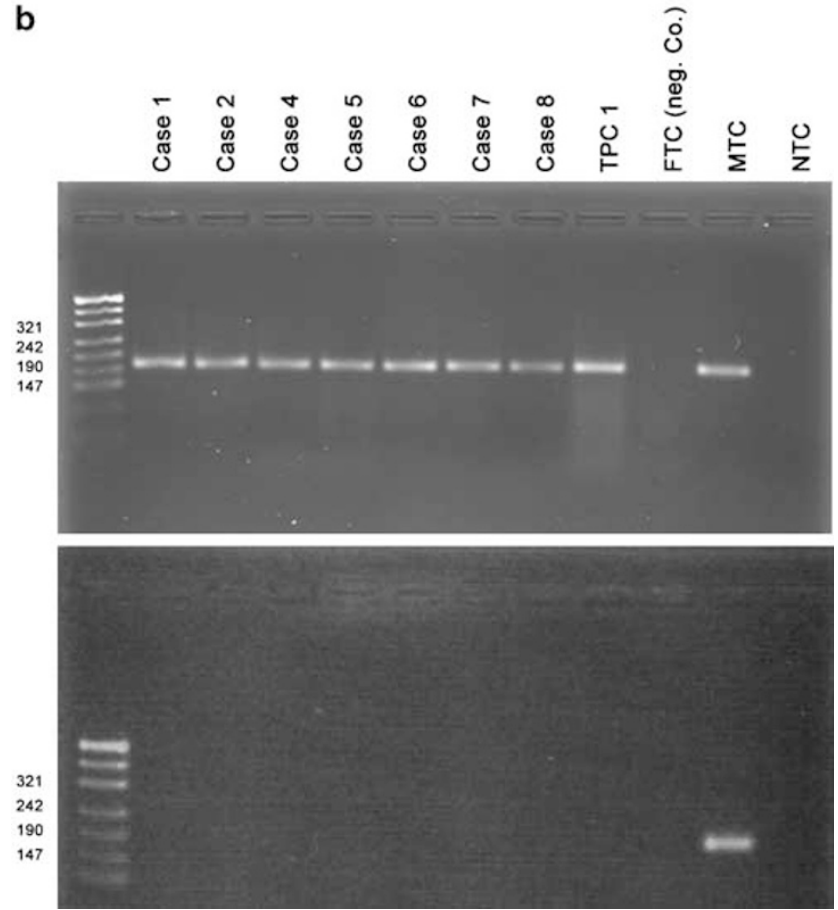

Figure 3 (a) Amplification of 236-bp sequence of c- $N$-ras cDNA for proving RNA integrity. All samples except case 3 and all controls showed detectable levels of $N$-ras transcripts. (b) Screening of the remaining seven cases (excluding case 3) for $R E T$ gene arrangements. Amplification of the fragments corresponding to the TK (above) and EC domains (down) of RET demonstrate expression of TK lacking the EC domain. The generation of both amplicons is demonstrated in the wild-type RET (MTC). TPC1 and FTC served as positive and negative control of the TK domain.

seven samples showed the expression of the specific TK band of $155 \mathrm{bp}$ in the absence of the EC band of $184 \mathrm{bp}$ in all cases (Figure $3 \mathrm{~b}$ ). This was also confirmed by nucleotide sequence analysis (data not shown). The immunohistochemical examination of all tumour samples with antibodies against calcitonin was consistently negative (data not shown). These results suggest the presence of a $R E T / \mathrm{PTC}$ rearrangement in all seven cases investigated. The additional analysis of RET/PTC 1 and RET/PTC 3 rearrangements revealed RET/PTC1 rearrangement in $2 / 7$ cases $(28 \%)$ and $R E T / \mathrm{PTC} 3$ in $1 / 7$ cases $(14 \%)$ (Figure 4a). Sequence analysis of $R E T / \mathrm{PTC} 1$ (case 1) and RET/PTC 3 (case 2) are shown in Figure $4 \mathrm{~b}$.

\section{Discussion}

Several studies have shown that BRAF mutations and $R E T / \mathrm{PTC}$ rearrangements are strictly alternative pathways in the etiopathogenesis of $\mathrm{PTC}^{28-30}$ although one study reported a single patient with coexisting $B R A F$ mutation and RET/PTC rearrangement. ${ }^{33}$ Activating mutations of $B R A F$ represent the most common genetic alteration in PTCs with reported frequencies ranging from $29^{26}$ to $83 \%^{34}$ with an overall prevalence of approximately $45 \%$ (reviewed by $\mathrm{Xing}^{20}$ ). The T1799A transversion in exon 15 has been associated with distinct histological subtypes of PTC (the highest prevalence was shown for the tall cell variant with $77 \%$, followed by the conventional type with $60 \%$ ). ${ }^{24,28,34-40}$ The lowest prevalence was reported for the follicular variant $(12 \%)$ (reviewed by $\mathrm{Xing}^{20}$ ). A literature search revealed seven cases of diffuse sclerosing variant of PTC examined for BRAF V599E mutation so far (Table 3). ${ }^{24,38-40}$ In accordance with the findings of the present study, four out of these seven cases lacked $B R A F$ mutation..$^{24,38,40}$ In contrast, Salvatore et $a,^{39}$ examining both thyroid aspirates and corresponding paraffin-embedded surgical samples by SSCP and DNA sequencing, found BRAF mutations in two out of three patients $(66 \%)$ with this rare variant. These discrepancies either indicate that $B R A F$ mutations may be the initiating genetic event in a small proportion of this subtype or Salvatore et al may have included cases not representing 'true' cases.

In order to confirm our negative $B R A F$ results in all cases, we performed the RET/PTC rearrangement screening method originally described by Nikiforov et $a l,{ }^{16}$ which has been subsequently used by other investigators for the general demonstration of RET/ PTC rearrangements. ${ }^{41,42}$ Using this method, we found a consistent and reproducible lack of the EC domain in all seven cases investigated, whereas the TK domain of RET could be equally consistent and reproducible demonstrated in all cases. Subsequently, RET/PTC types 1 and 3 rearrangements were found in three cases, suggesting that the remaining four cases may harbour one of the rare types of $R E T / \mathrm{PTC}$ rearrangement. However, owing to the study of Learoyd et $a l^{43}$ demonstrating a different prevalence of the RET TK domain mRNA using different sets of primers, we are aware that our results have to be interpreted with caution. As we used RT-PCR with RET TK exon 15/17 primers that resulted in the study of Learoyd et al in a significantly lower prevalence of $24 \%$ (12 of 50 PTC) of the RET TK domain compared with RET TK exon $12 / 13$ that was amplified in 35 of 50 PTC $(70 \%)$, it seems to be most likely that our results do not represent artefacts. An unwanted contamination with $\mathrm{C}$ cells leading to a false-positive TK domain result was virtually excluded by immunohistochemistry of the tissue samples investigated. In the light of our results, it is tempting to suggest for the 

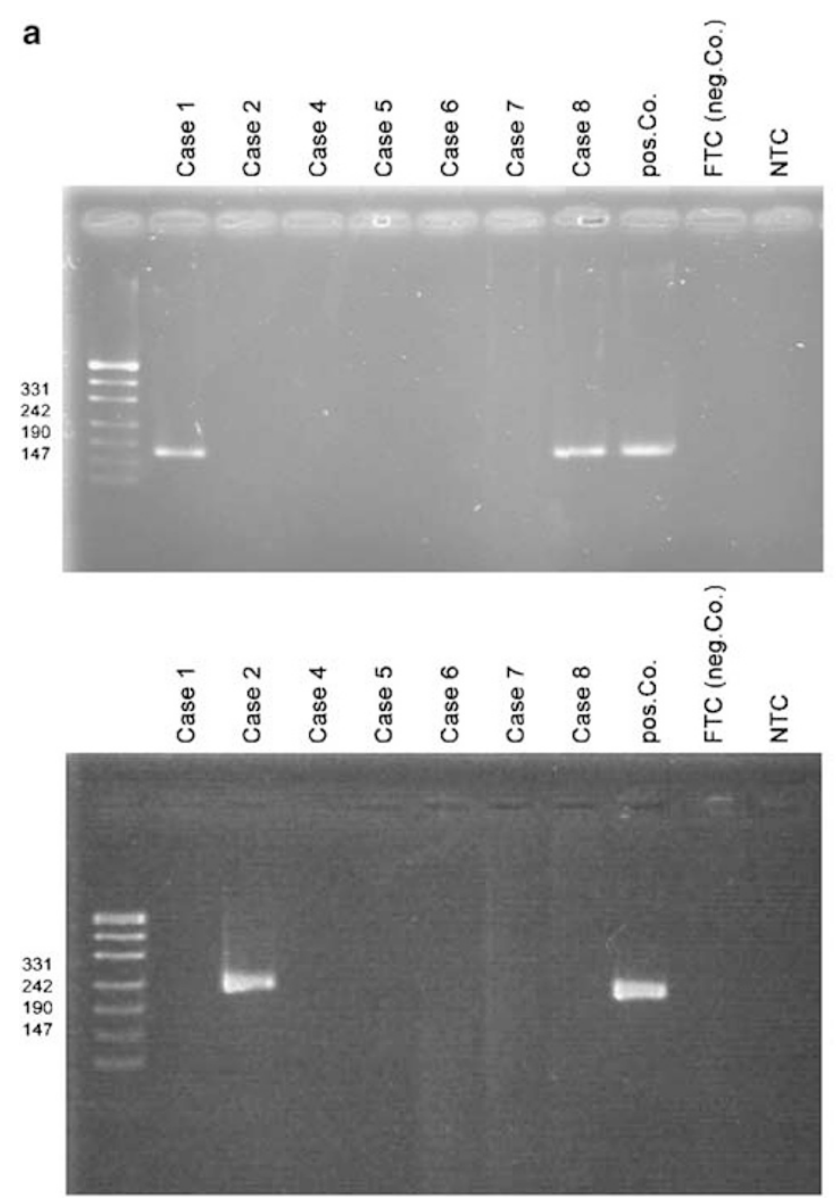

b
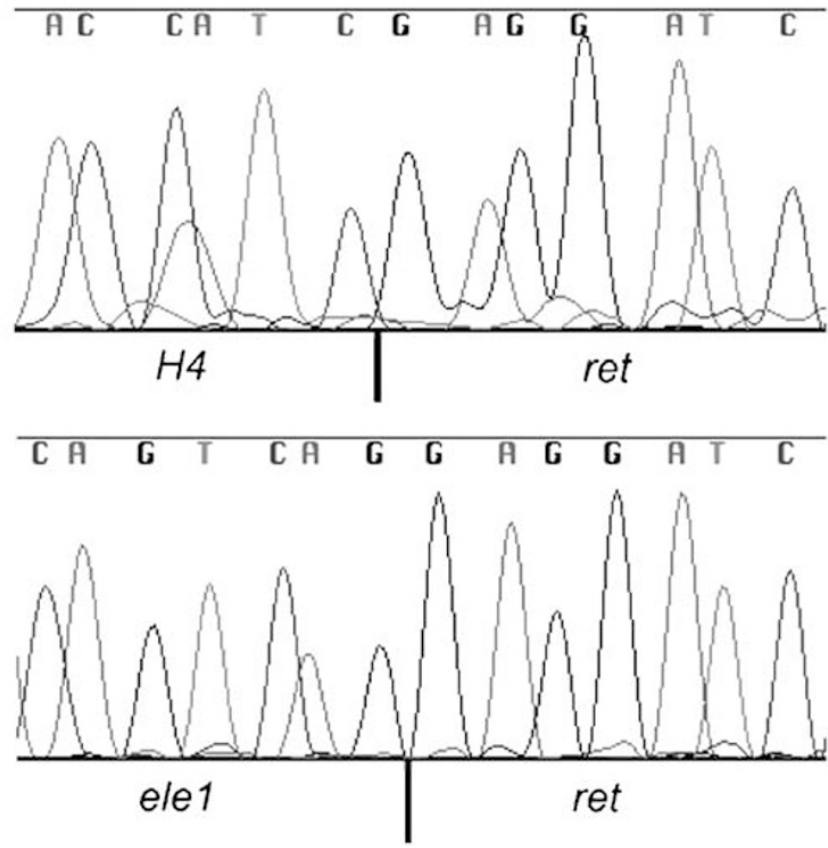

Figure 4 (a) RET/PTC 1 and 3 analysis by RT-PCR. Amplification of the samples demonstrate two cases harbouring RET/PTC 1 (cases 1 and 8, above). Case 2 shows RET/PTC 3 (down). (b) Sequence analysis of RET/PTC 1 (case 1, above) and RET/PTC 3 (case 2, down). The fusion points of the involved genes are indicated by vertical bars.

Table 3 Diffuse sclerosing variant of papillary thyroid carcinoma and $B R A F$

\begin{tabular}{lcl}
\hline Reference (no.) & Number of cases & BRAF (\%) \\
\hline Nikiforova et $a l^{24}$ & 1 & $0 / 1(0)$ \\
Puxeddu et $a l^{38}$ & 1 & $0 / 1(0)$ \\
Trovisco et $a l^{40}$ & 2 & $0 / 2(0)$ \\
Salvatore et $a l^{39}$ & 3 & $2 / 3(66)$ \\
Present study & 8 & $0 / 8(0)$ \\
\hline
\end{tabular}

remaining four cases that the occurrence of one of the alternative rearrangement types mostly but not exclusively (RET/ELKS) found in post-radiationinduced PTCs (RET/PTC 5, RET/PTC 6, RET/PTC 7, RET/KTN 1, RET/RFG 8, RET/PCM-1). ${ }^{44}$

$R E T / \mathrm{PTC} 1$ and RET/PTC3 account for $>90 \%$ of all rearrangements found in PTCs. ${ }^{18}$ Various types of $R E T / \mathrm{PTC}$ rearrangement have been correlated with histological variants with RET/PTC1 being more common in tumours with pure or predominantly papillary growth. ${ }^{45}$ Obvious correlation between different types of RET/PTC and morphological
Table 4 Diffuse sclerosing variant of papillary thyroid carcinoma and RET/PTC rearrangements

\begin{tabular}{llcc}
\hline Reference (no.) & Number of cases & RET/PTC1 & RET/PTC3 \\
\hline Nikiforov et $a l^{16}$ & 3 radiation induced & $1 / 3$ & $2 / 3$ \\
& 2 sporadic & $2 / 2$ & $0 / 2$ \\
${\text { Bongarzone } \text { et } a l^{49}}^{19}$ 1 sporadic & $1 / 1$ & $0 / 1$ \\
Thomas et $a l^{47}$ & 4 radiation induced & $2 / 4$ & $1 / 4$ \\
Salvatore et $a l^{39}$ & $3^{\text {a }}$ (1/3 positive) & a & a \\
Adeniran et $a l^{48}$ & $2^{\text {a }}$ (2/2 positive) & a & a \\
Present study & 7 & $2 / 7$ & $1 / 7$ \\
\hline
\end{tabular}

${ }^{\mathrm{a}}$ RET/PTC rearrangement type not described in detail.

features have also been observed in tumours from children exposed to radiation after the Chernobyl accident. The solid variant of PTC correlated strongly with $R E T / \mathrm{PTC} 3$, whereas the conventional type was regularly referred to RET/PTC1. ${ }^{16,46,47}$ To our knowledge, RET/PTC rearrangement has been reported in 15 diffuse sclerosing variants so far, presumably including eight (sporadic) cases without radiation exposure history and seven post-Cherno- 
byl cases (Table 4). ${ }^{16,39,47-49}$ Excluding six cases, which do not explicitly describe the type of rearrangement, ${ }^{39,48}$ RET/PTC1 rearrangement was found in six (four with radiation history) out of nine $(67 \%)$ patients, the remaining three cases with radiation exposure exhibited RET/PTC3 $(33 \%)$ rearrangement.

$R E T / \mathrm{PTC}$ rearrangements have also been reported to show a higher prevalence in children and young adults $^{50-52}$ with RET/PTC 1 representing the major type. As the average age of patients with this subtype is considerably lower compared with other types of PTC, ${ }^{10,11}$ it is not surprising that $R E T / \mathrm{PTC}$ rearrangement represents the initiating genetic event of this variant. However, it is intriguing to note that one of our patients was aged 61 at the initial diagnosis (showing RET/PTC type 1 rearrangement).

Heterogeneity in distribution of RET/PTC rearrangement within one tumour has been demonstrated by two studies. ${ }^{53,54}$ Using fluorescence in situ hybridization (FISH), Unger et $a l^{53}$ revealed that within a single PTC, only a subset of tumour cells (not more than $46 \%$ ) showed RET/PTC rearrangement beside areas completely lacking tumour cells with RET/PTC rearrangement. In contrast to these studies, Zhu et a $5^{54}$ using FISH technique reported that the vast majority (50-86\%) if not all tumour cells carried the rearrangement. They also provide evidence of a broad variability in the prevalence of $R E T / P T C$ rearrangement owing to usage of different detection methods (three different RT-PCR methods, FISH, Southern blot analysis). The macrodissection method used for this study, ${ }^{36}$ however, seems to be well suited to obtain sufficient amounts of RNA from representative tumour areas to demonstrate RET/PTC rearrangement.

Our results do not allow to draw conclusions concerning a correlation between type of RET/PTC rearrangement and clinical behaviour or nodal metastasis, respectively, as described by others. ${ }^{45,55,56}$ All three patients with an identified rearrangement type initially presented with locally advanced stage of disease and nodal involvement, which has presumably to be attributed to this special variant rather than to the underlying genetic event.

Melillo et $a l^{57}$ have shown the oncogenic proteins encoded either by $B R A F$ or rearranged RET/PTC genes work along the same signalling cascade with each of them being a possible focus of targeted cancer therapy. BAY 43-9006, a biaryl urea that targets RAF-1 and $B R A F$ as well as other $\mathrm{TKs}^{58}$ is now being tested in a phase II study of patients with locally advanced, metastatic, or recurrent thyroid cancer in the United States. ZD6474, a low molecular TK inhibitor was shown in vivo to block phosphorylation and signalling of both RET/PTC3 and RET/MEN2B, ${ }^{59}$ may be a promising candidate for targeted therapy of diffuse sclerosing variant of PTC.

\section{References}

1 DeLellis RA, Lloyd RV, Heitz PU, et al. (eds). World Health Organization Classification of Tumours. Pathology and Genetics of Endocrine Organs. IARC Press: Lyon, 2004.

2 Hundahl SA, Cady B, Cunningham MP, et al. Initial results from a prospective cohort study of 5583 cases of thyroid carcinoma treated in the united states during 1996. U.S. and German Thyroid Cancer Study Group. An American College of Surgeons Commission on Cancer Patient Care Evaluation study. Cancer 2000; 89:202-217.

3 Lam AK, Lo CY, Lam KS. Papillary carcinoma of thyroid: a 30-yr clinicopathological review of the histological variants. Endocr Pathol 2005;16:323-330.

4 Carcangiu ML, Bianchi S. Diffuse sclerosing variant of papillary thyroid carcinoma. Clinicopathologic study of 15 cases. Am J Surg Pathol 1989;13:1041-1049.

5 Fujimoto Y, Obara T, Ito Y, et al. Diffuse sclerosing variant of papillary carcinoma of the thyroid. Clinical importance, surgical treatment, and follow-up study. Cancer 1990;66:2306-2312.

6 Imamura Y, Kasahara Y, Fukuda M. Multiple brain metastases from a diffuse sclerosing variant of papillary carcinoma of the thyroid. Endocr Pathol 2000;11:97-108.

7 Hedinger C, Williams ED, Sobin LH. Histological Typing of Thyroid Tumours. International Histological Classification of Tumours. 2nd edn. Springer-Verlag: Heidelberg, New York, Tokyo, 1988.

8 Rosai J. Thyroid gland. In: Rosai J, Ackerman L (eds). Rosai and Ackerman's Surgical Pathology, 9th edn. Mosby: Edinburgh, London, New York, Oxford, Philadelphia, St Louis, Sydney, Toronto, 2004, pp 515-594.

9 Sywak M, Pasieka JL, Ogilvie T. A review of thyroid cancer with intermediate differentiation. J Surg Oncol 2004;86:44-54.

10 Lam AK, Lo CY. Diffuse sclerosing variant of papillary carcinoma of the thyroid: a 35-year comparative study at a single institution. Ann Surg Oncol 2006;13: 176-181.

11 Thompson LD, Wieneke JA, Heffess CS. Diffuse sclerosing variant of papillary thyroid carcinoma: a clinicopathologic and immunophenotypic analysis of 22 cases. Endocr Pathol 2005;16:331-348.

12 Schroder S, Bay V, Dumke K, et al. Diffuse sclerosing variant of papillary thyroid carcinoma. S-100 protein immunocytochemistry and prognosis. Virchows Arch A Pathol Anat Histopathol 1990;416:367-371.

13 Vickery Jr AL, Carcangiu ML, Johannessen JV, et al. Papillary carcinoma. Semin Diagn Pathol 1985;2: 90-100.

14 Fugazzola L, Pilotti S, Pinchera A, et al. Oncogenic rearrangements of the RET proto-oncogene in papillary thyroid carcinomas from children exposed to the Chernobyl nuclear accident. Cancer Res 1995;55: 5617-5620.

15 Klugbauer S, Lengfelder E, Demidchik EP, et al. High prevalence of RET rearrangement in thyroid tumors of children from Belarus after the Chernobyl reactor accident. Oncogene 1995;11:2459-2467.

16 Nikiforov YE, Rowland JM, Bove KE, et al. Distinct pattern of ret oncogene rearrangements in morphological variants of radiation-induced and sporadic thyroid papillary carcinomas in children. Cancer Res 1997;57:1690-1694. 
17 Santoro M, Melillo RM, Carlomagno F, et al. Molecular mechanisms of RET activation in human cancer. Ann N Y Acad Sci 2002;963:116-121.

18 Fagin JA. Perspective: lessons learned from molecular genetic studies of thyroid cancer-insights into pathogenesis and tumor-specific therapeutic targets. Endocrinology 2002;143:2025-2028.

19 Robinson MJ, Cobb MH. Mitogen-activated protein kinase pathways. Curr Opin Cell Biol 1997;9:180-186.

20 Xing M. BRAF mutation in thyroid cancer. Endocr Relat Cancer 2005;12:245-262.

21 Davies H, Bignell GR, Cox C, et al. Mutations of the BRAF gene in human cancer. Nature 2002;417: 949-954.

22 Ciampi R, Nikiforov YE. Alterations of the BRAF gene in thyroid tumors. Endocr Pathol 2005;16:163-172.

$23 \mathrm{Xu}$ X, Quiros RM, Gattuso P, et al. High prevalence of BRAF gene mutation in papillary thyroid carcinomas and thyroid tumor cell lines. Cancer Res 2003;63: 4561-4567.

24 Nikiforova MN, Kimura ET, Gandhi M, et al. BRAF mutations in thyroid tumors are restricted to papillary carcinomas and anaplastic or poorly differentiated carcinomas arising from papillary carcinomas. J Clin Endocrinol Metab 2003;88:5399-5404.

25 Xing M, Westra WH, Tufano RP, et al. BRAF mutation predicts a poorer clinical prognosis for papillary thyroid cancer. J Clin Endocrinol Metab 2005;90: 6373-6379.

26 Namba H, Nakashima M, Hayashi T, et al. Clinical implication of hot spot BRAF mutation, V599E, in papillary thyroid cancers. J Clin Endocrinol Metab 2003;88:4393-4397.

27 Begum S, Rosenbaum E, Henrique $\mathrm{R}$, et al. BRAF mutations in anaplastic thyroid carcinoma: implications for tumor origin, diagnosis and treatment. Mod Pathol 2004;17:1359-1363.

28 Frattini M, Ferrario C, Bressan P, et al. Alternative mutations of BRAF, RET and NTRK1 are associated with similar but distinct gene expression patterns in papillary thyroid cancer. Oncogene 2004;23: 7436-7440.

29 Kimura ET, Nikiforova MN, Zhu Z, et al. High prevalence of BRAF mutations in thyroid cancer: genetic evidence for constitutive activation of the RET/PTC-RAS-BRAF signaling pathway in papillary thyroid carcinoma. Cancer Res 2003;63:1454-1457.

30 Soares P, Trovisco V, Rocha AS, et al. BRAF mutations and RET/PTC rearrangements are alternative events in the etiopathogenesis of PTC. Oncogene 2003;22: 4578-4580.

31 Musholt PB, Imkamp F, von WR, et al. RET rearrangements in archival oxyphilic thyroid tumors: new insights in tumorigenesis and classification of Hurthle cell carcinomas? Surgery 2003;134:881-889.

32 Chua EL, Wu WM, Tran KT, et al. Prevalence and distribution of ret/ptc 1, 2, and 3 in papillary thyroid carcinoma in New Caledonia and Australia. J Clin Endocrinol Metab 2000;85:2733-2739.

33 Domingues R, Mendonca E, Sobrinho L, et al. Searching for RET/PTC rearrangements and BRAF V599E mutation in thyroid aspirates might contribute to establish a preoperative diagnosis of papillary thyroid carcinoma. Cytopathology 2005;16:27-31.

$34 \mathrm{Kim}$ KH, Kang DW, Kim SH, et al. Mutations of the BRAF gene in papillary thyroid carcinoma in a Korean population. Yonsei Med J 2004;45:818-821.
35 Cohen Y, Rosenbaum E, Clark DP, et al. Mutational analysis of BRAF in fine needle aspiration biopsies of the thyroid: a potential application for the preoperative assessment of thyroid nodules. Clin Cancer Res 2004;10:2761-2765.

36 Fugazzola L, Mannavola D, Cirello V, et al. BRAF mutations in an Italian cohort of thyroid cancers. Clin Endocrinol (Oxford) 2004;61:239-243.

37 Fukushima T, Suzuki S, Mashiko M, et al. BRAF mutations in papillary carcinomas of the thyroid. Oncogene 2003;22:6455-6457.

38 Puxeddu E, Moretti S, Elisei R, et al. BRAF(V599E) mutation is the leading genetic event in adult sporadic papillary thyroid carcinomas. J Clin Endocrinol Metab 2004;89:2414-2420.

39 Salvatore G, Giannini R, Faviana P, et al. Analysis of BRAF point mutation and RET/PTC rearrangement refines the fine-needle aspiration diagnosis of papillary thyroid carcinoma. J Clin Endocrinol Metab 2004; 89:5175-5180.

40 Trovisco V, Vieira dC I, Soares P, et al. BRAF mutations are associated with some histological types of papillary thyroid carcinoma. J Pathol 2004;202:247-251.

41 Elisei R, Romei C, Vorontsova T, et al. RET/PTC rearrangements in thyroid nodules: studies in irradiated and not irradiated, malignant and benign thyroid lesions in children and adults. J Clin Endocrinol Metab 2001;86:3211-3216.

42 Santoro M, Thomas GA, Vecchio G, et al. Gene rearrangement and Chernobyl related thyroid cancers. Br J Cancer 2000;82:315-322.

43 Learoyd DL, Messina M, Zedenius J, et al. RET/PTC and RET tyrosine kinase expression in adult papillary thyroid carcinomas. J Clin Endocrinol Metab 1998;83: 3631-3635.

44 Nikiforov YE. RET/PTC rearrangement in thyroid tumors. Endocr Pathol 2002;13:3-16.

45 Tallini G, Santoro M, Helie $M$, et al. RET/PTC oncogene activation defines a subset of papillary thyroid carcinomas lacking evidence of progression to poorly differentiated or undifferentiated tumor phenotypes. Clin Cancer Res 1998;4:287-294.

46 Rabes HM, Demidchik EP, Sidorow JD, et al. Pattern of radiation-induced RET and NTRK1 rearrangements in 191 post-chernobyl papillary thyroid carcinomas: biological, phenotypic, and clinical implications. Clin Cancer Res 2000;6:1093-1103.

47 Thomas GA, Bunnell H, Cook HA, et al. High prevalence of RET/PTC rearrangements in Ukrainian and Belarussian post-Chernobyl thyroid papillary carcinomas: a strong correlation between RET/PTC3 and the solid-follicular variant. J Clin Endocrinol Metab 1999;84:4232-4238.

48 Adeniran AJ, Zhu Z, Gandhi M, et al. Correlation between genetic alterations and microscopic features, clinical manifestations, and prognostic characteristics of thyroid papillary carcinomas. Am J Surg Pathol 2006;30:216-222.

49 Bongarzone I, Vigneri P, Mariani L, et al. RET/ NTRK1 rearrangements in thyroid gland tumors of the papillary carcinoma family: correlation with clinicopathological features. Clin Cancer Res 1998;4: 223-228.

50 Bongarzone I, Fugazzola L, Vigneri P, et al. Age-related activation of the tyrosine kinase receptor protooncogenes RET and NTRK1 in papillary thyroid carcinoma. J Clin Endocrinol Metab 1996;81:2006-2009. 
51 Fenton CL, Lukes Y, Nicholson D, et al. The ret/PTC mutations are common in sporadic papillary thyroid carcinoma of children and young adults. J Clin Endocrinol Metab 2000;85:1170-1175.

52 Nakazawa T, Kondo T, Kobayashi Y, et al. RET gene rearrangements (RET/PTC1 and RET/PTC3) in papillary thyroid carcinomas from an iodine-rich country (Japan). Cancer 2005;104:943-951.

53 Unger K, Zitzelsberger H, Salvatore G, et al. Heterogeneity in the distribution of RET/PTC rearrangements within individual post-Chernobyl papillary thyroid carcinomas. J Clin Endocrinol Metab 2004;89:4272-4279.

54 Zhu Z, Ciampi R, Nikiforova MN, et al. Prevalence of RET/PTC rearrangements in thyroid papillary carcinomas: effects of the detection methods and genetic heterogeneity. J Clin Endocrinol Metab 2006;91: 3603-3610.

55 Sugg SL, Ezzat S, Rosen IB, et al. Distinct multiple RET/PTC gene rearrangements in multifocal papillary thyroid neoplasia. J Clin Endocrinol Metab 1998;83: 4116-4122.

56 Viglietto G, Chiappetta G, Martinez-Tello FJ, et al. $\mathrm{RET} / \mathrm{PTC}$ oncogene activation is an early event in thyroid carcinogenesis. Oncogene 1995;11: 1207-1210.

57 Melillo RM, Castellone MD, Guarino V, et al. The RET/ PTC-RAS-BRAF linear signaling cascade mediates the motile and mitogenic phenotype of thyroid cancer cells. J Clin Invest 2005;115:1068-1081.

58 Wilhelm SM, Carter C, Tang L, et al. BAY 43-9006 exhibits broad spectrum oral antitumor activity and targets the RAF/MEK/ERK pathway and receptor tyrosine kinases involved in tumor progression and angiogenesis. Cancer Res 2004;64:7099-7109.

59 Carlomagno F, Vitagliano D, Guida T, et al. ZD6474, an orally available inhibitor of KDR tyrosine kinase activity, efficiently blocks oncogenic RET kinases. Cancer Res 2002;62:7284-7290. 